\title{
Update and Debate Issues in Surgical Treatment of Middle and Low Rectal Cancer
}

\author{
Nam Kyu Kim, Min Sung Kim, Sami F. AL-Asari \\ Department of Surgery, Yonsei University College of Medicine, Seoul, Korea
}

Based on a review of the literature, this paper provides an update on surgical treatment of middle and low rectal cancer and discusses issues of debate surrounding that treatment. The main goal of the surgical treatment of rectal cancer is radical resection of the tumor and surrounding lymphatic tissue. Local excision of early rectal cancer can be another treatment option, in which the patient can avoid possible complications related to radical surgery. Neoadjuvant chemoradiation therapy (CRT) has been recommended for patients with cT3-4N0 or any $\mathrm{T} N+$ rectal cancer because CRT shows better local control and less toxicity than adjuvant CRT. However, recent clinical trials showed promising results for local excision after neoadjuvant CRT in selected patients with low rectal cancer. In addition, the "wait and see" concept is another modality that has been reported for the management of tumors that show complete clinical remission after neoadjuvant CRT. Although radical surgery for middle and low rectal cancer is the cornerstone therapy, an ultralow anterior resection with or without intersphincteric resection (ISR) has become an alternative standard surgical method for selected patients. Many studies have reported on the oncological safety of the ISR, but few of them have addressed the issue the functional outcome. Furthermore, an abdominoperineal resection (APR) has problems with high rates of tumor perforations and positive circumferential resection margins, and those factors have contributed to its having a high rate of local recurrence and a poor survival rate for rectal cancer compared with sphincter-saving procedures. Recently, great efforts have been made to reduce these problems, and the total levator excision or the extended APR concept has emerged. Surgical management for low rectal cancer should aim to radically excise the tumor and to preserve as much of the sphincter function as possible by using multidisciplinary approaches. However, further prospective clinical trials are needed for tailored treatment of rectal cancer patients.

Keywords: Rectal neoplasms; Local excision; Neoadjuvant chemoradiation therapy; Multidisciplinary approach

\section{INTRODUCTION}

Based on a review of the literature, this paper provides an update on surgical treatment of middle and low rectal cancer and discusses issues of debate surrounding that treatment. Locoregional tumor control in rectal cancer surgery has improved significantly over the last 20 years due to the introduction of the total mesorectal

Received: October 16, 2012 - Accepted: October 29, 2012

Correspondence to: Nam Kyu Kim, M.D.

Department of Surgery, Yonsei University College of Medicine, 50 Yonsei-ro, Seodaemun-gu, Seoul 120-749, Korea

Tel: +82-2-2228-2117, Fax: +82-2-313-8289

E-mail:namkyuk@yuhs.ac

(C) 2012 The Korean Society of Coloproctology

This is an open-access article distributed under the terms of the Creative Commons Attribution NonCommercial License (http://creativecommons.org/licenses/by-nc/3.0) which permits unrestricted noncommercial use, distribution, and reproduction in any medium, provided the original work is properly cited. excision (TME), which allows complete removal of the intact mesorectum. After the concept of TME was adopted as the standard treatment for rectal cancer, the rate of local recurrence and the functional outcomes have improved. Furthermore, a multidisciplinary approach and the use of accurate local staging with transrectal ultrasound (TRUS) and rectal magnetic resonance imaging (MRI) has become more popular in Korea.

Preoperative chemoradiation therapy (CRT) for rectal cancer has become more common in Korea based on National Comprehensive Cancer Network (NCCN) guidelines. However, a wide range of tumor responses from complete remission to no response have been observed. Based on a rectal cancer study by a Dutch group, preoperative CRT followed by surgery results in significantly better local control of resectable rectal cancer. [1,2] Preoperative short-course radiotherapy (5 Gy for 5 consecutive days) followed by immediate TME for CT3-4N0 or any T N+ rectal cancer without a threatening circumferential resection margin (CRM) is a 
standard treatment in The Netherlands. Long-course CRT is indicated for more locally advanced rectal cancer in European countries. However, in North America, preoperative 5-fluorouracil (5-FU)-based long-course CRT followed by delayed surgery has been recommended as a standard treatment for advanced rectal cancers with stages worse than cT3N0. Recently, long-course neoadjuvant CRT has become more popular in Korea.

Distal rectal cancer has been regarded as a challenging disease in terms of oncologic and functional outcomes. In addition to the standard low anterior resection (LAR) for distal rectal cancer, an ultralow anterior resection (ULAR) with or without intersphincteric resection (ISR) has been reported to be safe and feasible by many studies [3-6]. However, the anal sphincter function and colorectal anastomotic site stricture were not well studied.

The abdominoperineal resection (APR) is a standard operative technique for advanced distal rectal cancer. However, the high rate of positive CRMs may result in a high local recurrence rate and subsequently a poor oncologic outcome. The extended APR (total levator excision) has been advocated to avoid a positive CRM and to improve the oncologic outcome. It shows a decreased rate of local recurrence, which can be explained by the reduced rate of positive CRMs and reduced tumor perforation.

In regard to the preservation of the anal sphincter function, CRT has been proposed to downsize and downstage the tumor. Thus, sphincter preservation with acceptable anal function and with an oncological outcome similar to that of radical surgery has been reported. Moreover, early rectal cancer showed good response to neoadjuvant CRT. Transanal local excision (TAE) or wait and see treatment option has been recommended for selected cases with good response. Due to the inaccurate prediction of positive nodes by conventional imaging studies, these treatment options were justified only on the basis of a small number of clinical trials.

Indeed, an average of $20 \%$ pathologic complete response (pCR) is seen after neoadjuvant CRT. Multiple clinical trials have been conducted with altered chemotherapy regimens to achieve a higher rate of pCR. However, those studies failed to demonstrate any increase in the rate of $\mathrm{pCR}$ and were adversely affected by side effects and toxicities $[7,8]$. The aim of this article is to review current update and debate issues in the surgical treatment of middle and low rectal cancer through a literature review.

\section{TREATMENT OPTIONS}

\section{TAE}

Radical resection for rectal cancer itself has significant morbidities such as anastomotic leakage (5 to $15 \%$ ), injury to the hypogastric and the pelvic nerves, and bowel dysfunctions such as tenesmus, irregular bowel movement, soiling, urgency, etc. However, these complications can be avoided by using local excision of the tumor. Usually, TRUS is a quite reasonable diagnostic modality for assessing the depth of invasion of rectal cancer. Early rectal cancer such as $\mathrm{T} 1$ or $\mathrm{T} 2$ can be more accurately assessed by using
TRUS in a high-frequency mode.

Patient selection and appropriate consideration of adjuvant therapy are crucial to treatment. Local excision does not allow regional nodal dissection; thus, patients may be incorrectly staged as nodenegative on the basis of TRUS or MRI. Since transanal endoscopic microsurgery (TEM) was reported by Buess et al. [9] from Germany, it has been shown to have several merits compared to conventional TAE. TEM can provide a full thickness excision without fragmentation of the specimen and an adequate negative resection margin. The advantages of TAE are avoidance of abdominal incision, pelvic dissection, and colorectal anastomosis. Its major disadvantages are the potential for incomplete excision of the tumor and the absence of a lymphadenectomy. Indications for a TAE based on NCCN guidelines are tumor location within $8 \mathrm{~cm}$ from the anal verge, less than $30 \%$ circumferential involvement of the rectum, a tumor less than $3 \mathrm{~cm}$ in size, a clinically $\mathrm{T} 1$ tumor, and a mobile and well-differentiated adenocarcinoma. Technically, tumors that are too proximal, bulky and circumferentially involved are not suitable for local excision. A poorly-differentiated tumor with lymphovascular invasion shows a high risk for recurrence with local excision alone. The 5 -year rate of local recurrence for a pT1 tumor has been reported to range from 5 to $28 \%$, and the 5 -year disease-free survival rate from 64 to $93 \%$ [10-17]. For local excision of $\mathrm{T} 2$ lesions, the 5 -year rate of local recurrence has been reported to range from 8 to $24 \%$, and the 5-year disease-free survival rate from 76 to $93 \%[12,17-19]$.

When we reviewed the literature from 2000 to 2009 for T1 rectal cancer and compared the 5-year overall and disease-free survivals for both radical and local excision, we found that, although radical resection showed better results, the differences between them were not statistically significant (Table 1). Most of the studies on local excision for T1 cancer were small, retrospective analyses. Recent studies have helped define the risk of recurrence following local excision and have provided data concerning the success of salvage surgery in patients who experience local recurrence. There is ongoing interest in the role of transanal excision in conjunction with CRT for selected rectal cancers.

Salvage surgery may require a multivisceral pelvic resection, which has morbidity rates of $34 \%$ and $\mathrm{R} 0$ resection rates between $79 \%$ and $94 \%$. The 5 -year disease-free survival after salvage surgery ranges between 53\% and 59\%. Controversy still remains about whether or not patients who show local failure after local therapy can be treated effectively by using salvage surgery (LAR or APR) and whether or not the incidence of distant metastasis will be higher after salvage surgery.

Some authors reported promising results for salvage treatment. Garcia-Aguilar et al.[11] achieved good results from salvage treatment. Among 20 patients who had local or distant recurrence, 18 patients underwent additional therapy. Thirteen of them had radical surgery, and only 3 patients out of those 13 patients died from cancer recurrence. Moreover, Baron et al. [20] retrospectively analyzed patients treated with local excision. They compared $21 \mathrm{pa}-$ 
Table 1. Results of retrospective series comparing local excision with radical surgery for T1 rectal caner

\begin{tabular}{|c|c|c|c|c|c|}
\hline \multirow{2}{*}{ Study } & \multicolumn{2}{|c|}{ 5-yr local recurrence rate $(\%)$} & \multicolumn{2}{|c|}{ 5-yr overall survival rate (\%) } & \multirow{2}{*}{$\begin{array}{c}\text { Median } \\
\text { follow-up (yr) }\end{array}$} \\
\hline & Local excision & Radical resection & Local excision & Radical resection & \\
\hline Mellgren et al. (2000) [57] & 18 & 0 & 72 & 80 & 4.6 \\
\hline Nascimbeni et al. (2004) [15] & 6.6 & 2.8 & 72 & 90 & 8.1 \\
\hline Endreseth et al. (2005) [13] & 12 & 6 & 70 & 80 & NR \\
\hline Ptok et al. (2007) [16] & 5.1 & 1.4 & 84 & 92 & 3.5 \\
\hline Folkesson et al. (2007) [59] ${ }^{\text {a }}$ & 7 & 2 & 87 & 93 & NR \\
\hline Nash et al. (2009) [60] & 13.2 & 2.7 & 87 & 96 & 5.6 \\
\hline
\end{tabular}

NR, not reported.

${ }^{\mathrm{a}} \mathrm{Mix}$ of $\mathrm{T} 1$ and $\mathrm{T} 2$.

tients who underwent an immediate APR for adverse histological features to 21 patients who required an APR for local recurrence. They found that the disease-free survivals for the immediate and the salvage APR groups were $94 \%$ and $56 \%$, respectively. Therefore, careful patient selection is an important issue before proceeding with local excision.

Technically, TEM was developed to treat tumors that would otherwise be appropriate for TAE but resided too high in the rectum to be accessible by standard transanal techniques. The rectum is distended by the infusion of carbon dioxide through the rectoscope, and especially designed optical instruments permit stereoscopic vision. Precise resection of a lesion in the proximal rectum, normally inaccessible by standard transanal approaches, results in minimal discomfort or morbidity. Moore et al. [21] compared two groups of patients, TEM $(n=82)$ and conventional TAE $(n=87)$, with respect to margin clearance $(90 \%$ vs. $71 \%, \mathrm{P}=0.001)$ and nonfragmented specimens ( $94 \%$ vs. $65 \%, \mathrm{P}=0.001)$. Local recurrence was $5 \%$ vs. $27 \%(\mathrm{P}=0.004)$ for the TEM and the TAE groups, respectively. Christoforidis et al. [22] also compared TEM $(n=42)$ with conventional TAE $(n=129)$ for T1 and T2 tumor. They found that the surgical margin was positive in $2 \%$ and $16 \%$ of the patients who underwent the TEM and TAE, respectively $(\mathrm{P}=0.0001)$. The 5-year disease-free survival rates were $76 \%$ vs. $60.5 \%$ ( $\mathrm{P}=$ 0.029), respectively. Based on the two studies, TEM seemed to be much better treatment modality over local excision in term of oncologic safety.

Recently, the transanal endoscopic operation (TEO), transanal minimal invasive surgery (TAMIS), or robotic transanal surgery (RTS) has been reported $[23,24]$. In our institute, we started TEO for early rectal cancer in December 2011. We performed 19 TEOs by the end of October 2012. Most of them involved early rectal cancer, followed by carcinoid tumors and huge adenomas in decreasing order of frequency of occurrence. The median diameter was $1.9 \mathrm{~cm}$ (range, 0.2 to $6.0 \mathrm{~cm}$ ), and the median distance from the anal verge was $7 \mathrm{~cm}$ (range, 4 to $14 \mathrm{~cm}$ ). The median operative time was 102 minutes (range, 46 to 290 minutes). A positive resection margin was found in two cases $(10.6 \%)$ and fragmentation of the excised specimen was documented in one case (5.3\%). Out of 19 patients, one minor complication and three major complications requiring a second surgical intervention were reported. Immediate salvage surgery was performed for three patients (15.8\%). Recently, TAMIS has been performed using a single-port laparoscopic device applied to the anus. RTS using a single port applied to the anal canal and a robotic arm placed inside the anal canal has also been reported [23]. However, that study involved only a small number of cases; thus, large-scale, well-designed studies are needed to validate the safety and the feasibility of RTS.

Kitajima et al. [25] reported that the rate of regional lymph-node metastasis was variable depending on the depth of invasion. T1 tumors can be divided into three types based on their invasion of the submucosal layer. SM1 $(<1,000 \mu \mathrm{m})$ shows a risk of lymphnode metastasis of 1 to $3 \%$, SM2 $(1,000$ to $3,000 \mu \mathrm{m})$ shows a risk of lymph-node metastasis of 8 to $10 \%$, and SM3 $(>3,000 \mu \mathrm{m})$ shows a risk of lymph-node metastasis of 20 to $25 \%$. Therefore, radical surgery is recommended when the tumor has invaded the submucosa far beyond $1,000 \mu \mathrm{m}$.

After local excision, regular follow-up is recommended for lowrisk pT1 cancer. On the other hand, radical surgery is the recommended for pT1 cancer with high risk or for pT2 cancer. Neoadjuvant or adjuvant CRT with local excision has been reported to be an alternative option.

\section{Local excision followed by postoperative chemoradiation}

In general, a small mobile lesion in the rectum that is diagnosed as a clinically cT1 or cT2 tumor will not be treated with CRT as the first line of treatment because CRT itself has potential side effects, toxicity and related complications; thus, CRT can be considered as an overtreatment. If the final pathology shows pT1 cancer with high risk or $\mathrm{pT} 2$ cancer, the standard treatment is radical surgery. However, the next option will be adjuvant CRT, especially for 
patients with very low-lying rectal cancer. Although some surgeons recommend it, strong evidence for its use is still lacking.

Because we do not know the actual lymph node status after local excision for T1 lesions with high risk factors or T2 lesions, controversies have occurred about the safety of local excision followed by adjuvant CRT for the treatment of early rectal cancer.

Radiation Therapy Oncology Group protocol 89-02 has reported a local recurrence rate after local excision followed by CRT of around $4 \%$ in T1, $16 \%$ in T2, and 23\% in T3 cancers [26]. However, Min et al. [27] analyzed $76 \mathrm{~T} 1$ patients who received local excision only or local excision followed by adjuvant radiation therapy. The mean follow-up period was 84.9 months. During their follow-up period, the disease-free survival rate was $100 \%$ for local excision followed adjuvant radiation therapy and $76 \%$ for local excision. This study demonstrated the possible oncologic merits of local excision followed by radiation for the treatment of T1 lesions. However, the adverse effects of radiation therapy, especially those regarding anorectal function, have not been addressed. The Cancer and Leukemia Group B 8984 study showed the results of local excision for T1 $(n=59)$ and T2 $(n=51)$ cancers. T1 patients were regularly followed up, and long-course CRT was given to T2 patients [28]. With a median 7 years of follow-up, the 10 -year overall survival rates were $84 \%$ for $\mathrm{T} 1$ patients and $66 \%$ for T2 patients. The disease-free survival rates were $75 \%$ for $\mathrm{T} 1$ patients and $64 \%$ for T2 patients. The local recurrences were $8 \%$ and $18 \%$, respectively.

In general, local excision combined with CRT can be used for selected patients. However, tumor recurrence, the possibility of salvage surgery, and the risk of failure point to the need for more highly-motivated patients and for more discussion between the surgeon and the patients.

\section{Neoadjuvant CRT followed by local excision}

Preoperative long-course CRT has become the standard treatment for cT3-4N0 or any T N+ rectal cancer in Korea because it is associated with reduced radiation toxicity and late complications, as well as better local disease control. We can observe a wide range of tumor response after neoadjuvant CRT, which can be related to various factors such as radiation dose, chemotherapeutic drugs, timing of the surgery, tumor biology etc. However, preoperative accurate prediction of the complete response is still lacking, and the treatment for those patient who was suspected of having a complete response still is not clear. The standard treatment is radical surgery with either sphincter-preserving surgery or an APR.

A proctectomy with a TME itself has been demonstrated to have high morbidity. Various complications such as anastomotic leakage, wound infection, temporary stoma, sexual and voiding dysfunction and frequent bowel movement may develop. In addition to that, the APR needs a permanent stoma with associated morbidity and poor quality of life.

If a complete tumor response is observed, which means a nearly absent gross tumor or the presence of scar tissue based only on endoscopic and radiologic imaging, a full-thickness local excision may be an option. Oncologically, in a retrospective study of patients who received preoperative CRT, ypT0 patients showed a rate of lymph node metastasis of 0 to $17 \%$ (Table 2 ).

Table 2. Incidence of positive lymph nodes in patients with ypT0 after neoadjuvant chemoradiation

\begin{tabular}{|c|c|c|c|c|}
\hline Author & Institusion & Year & $\begin{array}{c}\text { No. of } \\
\text { patients } \\
\text { with pT0 }\end{array}$ & $\begin{array}{l}\text { No. with } \\
\text { positive } \\
\text { LN (\%) }\end{array}$ \\
\hline Onaitis et al. [61] & Duke & 2001 & 34 & $4(12)$ \\
\hline Medich et al. [62] & $\begin{array}{c}\text { Western } \\
\text { Pennsylvania }\end{array}$ & 2001 & 5 & $0(0)$ \\
\hline Hiotis et al. [63] & MSKCC & 2002 & 27 & $4(15)$ \\
\hline Zmora et al. [64] & Tel Aviv & 2003 & 17 & $2(12)$ \\
\hline Stipa et al. [65] & MSKCC & 2004 & 31 & $2(7)$ \\
\hline Bedrosian et al. [66] & MD Anderson & 2004 & 22 & $2(9)$ \\
\hline Kim et al. [67] & Goyang & 2006 & 45 & $1(2)$ \\
\hline Hughes et al. [68] & Northwood & 2006 & 23 & $4(17)$ \\
\hline Coco et al. [69] & Rome & 2007 & 56 & $1(2)$ \\
\hline Habr-Gama et al. [70] & Sao Paulo & 2008 & 21 & $1(5)$ \\
\hline
\end{tabular}

LN, lymph node; MSKCC, Memorial Sloan-Kettering Cancer Center.

Table 3. Outcome of patients with rectal cancer undergoing local excision after achieving ypT0 following neoadjuvant chemoradiation

\begin{tabular}{|c|c|c|c|c|}
\hline Study & Patients with pT0 & Follow-up & Local recurrence & Distant recurrence \\
\hline Schell et al. (2002) [71] & 8 & $48(18-105)$ & $0(0)$ & $1(12)$ \\
\hline Hershman et al. (2003) [72] & 7 & $33(3-120)$ & $0(0)$ & $0(0)$ \\
\hline Bonnen et al. (2004) [73] & 14 & $42(5-109)$ & $0(0)$ & $1(7)$ \\
\hline Stipa et al. (2004) [65] & 7 & $37(18-118)$ & $0(0)$ & NR \\
\hline Borschitz et al. (2008) [74] & 1 & $24(12-79)$ & $0(0)$ & $0(0)$ \\
\hline Nair et al. (2008) [75] & 19 & $64(6-153)$ & $1(5)$ & $1(5)$ \\
\hline Huh et al. (2008) [76] & 4 & $91(50-127)$ & $0(0)$ & $1(25)$ \\
\hline Kundel et al. (2010) [77] & 14 & $48(5-123)$ & $0(0)$ & $0(0)$ \\
\hline
\end{tabular}

Values are presented as median (range) or number (\%). 
Based on a literature review, we observed that ypT0 tumors after preoperative CRT followed by local excision showed a low rate of local recurrence of 0 to $5 \%$ and a distant metastasis rate of 0 to $25 \%$ (Table 3). This treatment modality has been assessed in smallsample-size prospective and retrospective studies, so it can be recommended as a treatment option for highly selective cases.

Lezoche et al. [29] reported on 35 patients with cT2N0 cancer who received preoperative CRT followed by local excision and compared them with 35 patients who had laparoscopic radical surgery. Interestingly, local recurrence was noted in 2 patients $(5.7 \%)$ and 1 patient $(2.8 \%)$, respectively. The 5 -year disease-free survival rates were not statistically different between the two groups. CARTS prospective multicenter trials investigated the role of a rectal-saving treatment modality using CRT and local excision. The inclusion criterion was patients with cT1-2-3N0M0 cancer to whom preoperative CRT $(2 \mathrm{~Gy} \times 25$ with capecitabine) had been given [30].

Even though there have been many debates about treatment modality, a couple of comparative studies have been reported. Callender et al. [31] compared local excision after standard 5-FUbased long-course CRT ( $\mathrm{n}=54$ ) with radical surgery with TME (n = 411) for T3 rectal cancer. A local excision was done for the patients: pCR $(n=23)$, microscopic residual disease $(n=17)$ and gross residual disease $(n=17)$. The mean follow-up period was 60 months. No statistical differences in the disease-free survivals, the disease-specific survivals or the overall survival rates were noted between the two groups. Therefore, they carefully proposed a local excision after standard long-course CRT for the treatment of T3 rectal cancer, with excellent tumor response, as an alternative treatment option. The nonrandomized phase II American College of Surgeons Oncology Group Z6041 trial evaluated patients with clinical T2N0 rectal cancer who received preoperative CRT followed by local excision [19]. Garcia-Aguilar et al. [19] found that the study had high pCRs of up to $44 \%$, but 39 patients (39\%) developed grade $>3$ CRT-related complications. Rectal pain was the most common complication. They concluded that further modifications to improve therapeutic efficacy were still needed.

Indeed, local excision after complete response remains a controversial issue due to the high risk of regional lymph-node metastasis and the difficulty in accurately staging the tumor after CRT. Neoadjuvant CRT followed by local excision is a very attractive treatment option, especially in distal and middle rectal cancer because patients can avoid radical surgery and subsequent complications. Therefore, we need to understand tumor biology better in order to identify those patients who will have complete response and to select them carefully for such a management modality.

\section{Wait and see}

About 10 to 20 percent of patients with locally advanced rectal cancer achieve a pCR after surgery following preoperative CRT. For the first time, Habr-Gama et al. [32] observed and followed patients with locally advanced rectal cancer who had a clinical complete tumor regression to preoperative CRT without any surgical intervention. They reported on a total of 265 rectal cancer patients who had undergone preoperative CRT. Out of the 265 patients, 71 showed a clinical complete response (cCR) according to their criteria. They were followed without any surgical intervention. Twenty-one patients in the control group who showed ypT0N0M0 cancer after radical surgery were followed as well. Interestingly, the 5-year overall survival was better in the observation group of patients, and the 5-year disease-free survival was poorer in the surgery group.

Consistent strategies are needed for more objective recognition of a cCR, as are reliable methods to confirm total eradication of the tumor. Based on the small number of patient in our study, we analyzed 29 patients who were given preoperative CRT, and we compared the endoscopic findings after preoperative CRT between the $\mathrm{CR}$ and the non-CR groups. White scarring, deep ulceration and telangiectasia were more commonly found in the CR group of patients than in the non-CR group. In addition to that, when the tumor volume was reduced by over $75 \%$ by MRI volumetry after preoperative CRT, the possibility of a pCR was higher. Those factors can be used for making a clinical decision when a cCR is strongly suspected [33].

Maas et al. [34] reported on 21 patients with cCR who were followed without any surgical intervention. The mean follow-up was $25 \pm 19$ months. He compared them with a control group of patients who underwent radical surgery. There were no differences in the 2-year disease-free survival and the overall survival rates between the two groups. They concluded that the "wait and see" option with strict selection criteria, up-to-date imaging techniques and follow-up was feasible and that the results were promising. The outcome was similar to that of patients with a pCR after surgery. The above mentioned studies were a retrospective study and the case numbers were also small. However, they showed that the observational group was comparable and even better in oncologic outcomes. Other retrospective studies have reported higher recurrence rates of 23 to $60 \%$. The reason these studies showed a wide range of recurrence rates is that most studies were heterogeneous in staging, inclusion criteria, study design and the timing of the assessment of a complete clinical response [35]

Although, multiple studies have reported the 'wait and see' option to be promising, there is still a lack of evidence about salvage surgery for local recurrence, the long-term oncologic and functional outcomes, and the quality of life. In our opinion, this treatment modality needs to be evaluated in the future based on more multiinstitutional, prospective, randomized, controlled trials using a large patient cohort. In addition, local excision biopsy for suspicious cCR lesions by using either a conventional method or TEM might be a suitable approach for assessment, and ypT status might be one of the parameters used to make a decision on further treatment.

Morbidity after local excision is of concern. Recently, Habr-Gama et al. [36] reported on 23 patients who received TEM after preop- 
erative CRT. That study showed a 30\% complication rate mainly in the primary site repair of the rectal wall. Complications like delayed healing, wound dehiscence and anorectal pain were observed.

\section{uLAR without ISR (CAA)}

Parks and Pery [37] reported coloanal anastomosis (CAA) after an ULAR for the treatment of distal rectal cancer to be feasible in terms of operative safety and oncologic outcomes. With the new revolution in operative techniques and instrumentation, CAA with either double stapling or hand sewing has become more popular. In our opinion, the definition of ULAR and CAA without ISR should have the following prerequisites: A total proctectomy should be done to the level of the anorectal ring just above the puborectalis muscle level. Then, reconstruction can be done by using either a double-stapled or hand-sewn anastomosis. Therefore, for CAA, the rectum and the surrounding mesorectum must be completely mobilized from the levator ani muscle.

Functionally, objective studies are still lacking, but subjective one show promising results, which is an important issue to improve the patient's quality life. The colonic J pouch procedure has been performed in our institute to reduce the postoperative frequency of bowel movements. However, straight CAA is still the preferred method in my practice, is easy to construct, and has a long-term functional outcome similar to that of the colonic J pouch.

Many literatures showed that after ULAR and CAA for distal rectal cancer, local recurrence was reported as 4 to $6 \%$, distant recurrence was 8 to 20\% [3-6]. In our institute, between 1997 and 2003, we analyzed 44 patients who underwent ULAR and CAA for the treatment of distal rectal cancer [4]. All cases were handsewn CAA, and reconstruction was done with either a colonic J pouch or a straight CAA. During a mean follow-up period of 32 months, 6 patients (13.6\%) showed fecal incontinence 1 year after surgery. Fortunately, most of them could be managed with conservative treatment such as diet control and antidiarrheal medicine. The 5-year disease-free survival rate was $68.9 \%$, and local recurrence was found in only 3 patients. Distant metastasis reported 2 patients and combined local and distant metastasis was seen in one patient. Oncologically, the procedure was found to be safe. In fact, the patients must be selected carefully for this procedure because the functional outcome is poor for some patients. For distal rectal cancer, careful patient selection is needed to achieve safe resection margins and to get better functional outcome, which might be affected by radiation therapy.

\section{ULAR with ISR}

In the past, the main goal of surgical treatment for the treatment of distal rectal cancer was a radical resection to achieve the best oncological outcome, and APR was the standard technique. However, with advances in preoperative CRT, as well as surgical instruments and skills, the use of the APR has decreased not only in our institute but also in other hospitals in Korea.

Rectal cancer close to the dentate line can be removed while pre- serving the anal external sphincter by using a combined resection of the internal anal sphincter, unless the tumor has invaded the external sphincter preoperatively. Functional outcome is a matter of concern for most surgeons. Tilney and Tekkis [38] analyzed 21 studies with 612 patients who underwent an ISR. They found the short-term outcomes to be acceptable and the mean rate of local recurrence to be $9.5 \%$ (0 to $31 \%$ ), with a 5-year overall survival rate of $81.5 \%$.

Portier et al. [39] analyzed 228 rectal cancer patients who underwent CAA between 1977 to 2007. Out of those 228 patients, 173 had an ISR, and 105 had a CAA without an ISR. The mean followup period was 66.8 months. The 5-year overall survival rates for local recurrence were $10.6 \%$ in the ISR group and $6.7 \%$ in the CAA group $(\mathrm{P}=0.405)$. The total 5 -year overall survival rates were $86.1 \%$ and $80 \%(\mathrm{P}=0.318)$, respectively. There were no differences in oncologic outcomes between CAA with and without ISR. If the external sphincter is not involved, circumferential tumor clearance can be achieved by resecting part of the internal sphincter. The influences of neoadjuvant treatment on the sphincter, long-term oncologic and functional outcomes still need to be assessed more carefully in the future.

Saito et al. [40] analyzed 228 patients who underwent ISR for the treatment of distal rectal cancer and followed them for 42 months. They found that the 5-year survival and disease-free survivals were $91.9 \%$ and $83.2 \%$, respectively. The 3-year local recurrence rate was $5.8 \%$. Schiessel et al. [41] reported on 38 patients who had an ISR. Ten percent had local recurrence, and the 5-year disease-free survival rate was $83.2 \%$. Rullier et al. [42] also reported on 92 patients who had an ISR for the treatment of distal rectal cancer. Fifty-eight of those 92 patients were followed for over 24 months, and they experienced only a $2 \%$ local recurrence while the 5-year disease-free survival was $70 \%$.

In a review of the literature comparing an ISR with CAA to an APR, we found that the local recurrence rates were 2 to $30 \%$ and 6 to $11 \%$, respectively, and the 5-year survival rates were 62 to $79.2 \%$ and 53 to $80 \%$, respectively. No differences in oncologic outcomes were noted between the two groups $[43,44]$. Also, Saito et al. [43] reported no differences in the overall survivals and the disease-free survivals between the ISR and the APR groups, and they concluded that the ISR was oncologically safe and acceptable and could reduce the number of APRs [45].

Moreover, Saito et al. [40] reported on 181 patients who underwent diverting stoma closure and who had been followed for 3 to 24 months. Among them, 110 patients had been assessed with the Wexner score, and their continence had been assessed with the Kirwan classification. The mean score was 7.8 after a 24-month follow-up, and use of the Kirwan continence classification showed that perfect continence was achieved in 36 patients, incontinence for flatus in 32 , occasional minor soiling in 25 , and frequent major soling in 7. None of them needed a colostomy for fecal incontinence [40]. Between 2004 and 2008, we analyzed 21 patients who had an ISR for the treatment of distal rectal cancer in our institute. 
Journal of The Korean Society of Update and Debate Issues in Surgical Treatment of Middle and Low Rectal Cancer

Coloproctology wam kn km ctal

The mean follow-up period was 12.9 months. Only 2 patients had local recurrence, and there was no fecal incontinence in $50 \%$ of the patients who underwent an ileostomy repair. However, that was an observational study with a small number of patients and a short follow-up period.

We noticed that patients who received an ISR after preoperative CRT sometimes suffered from anastomotic stricture, anal stool frequency, urgency, fragmentation, soiling, and fecal incontinence. Thus, we recommend that before planning this type of surgery, the anorectal sphincter function be evaluated by using anorectal manometry and the patient's age, motivation and activity be considered. In addition to that, 3D or 2D TRUS is important in sphincter evaluation and tumor invasion assessment.

\section{Rectal cancer within the surgical anal canal without invasion of the external sphincter complex}

If the tumor is located very close to the anorectal ring near the levator ani level, the coronal and axial views of rectal MRI are usually very important in assessing anal sphincter preservation (Fig. 1). The distance of the tumor from the anal verge is not sufficient to make a decision about anal sphincter preservation. Usually, for low rectal cancer, MRI cannot differentiate accurately between the tumor and fibrotic tissue after CRT. However, the decision for sphincter preservation might be changed if an accurate modality to differentiate between them with high specificity and sensitivity were available. 3D TRUS can give more details about the tumor and its relation to the sphincter complex.

\section{APR}

Miles introduced the APR in 1908 as a standard surgical treatment for distal rectal cancer. It is indicated for patients who show poor tumor response to preoperative CRT, tumor invasion into the external anal sphincter, possible invasion to the levatorani muscles, and poor anorectal function.

Because of advances in surgical techniques, surgical skills, preoperative CRT and tumor biologic behavior, recently, the number of patients who undergo an APR has been decreasing in Korea. Indeed, oncologic outcomes after an APR in comparison with those after a LAR are inferior in terms of the local recurrence and the long-term survival rates. A review of the literature comparing the APR to the LAR showed local recurrence rates of 15 to $33 \%$ and 1 to $13 \%$ for the two groups, respectively. The 5 -year survival rates were 38 to $60 \%$ and 57 to $76 \%$, respectively [46-49]. The main reason the APR showed poor oncologic outcomes was that the APR had a high risk of tumor perforation and CRM positivity. Kim et al. [50] analyzed 122 patients who received preoperative CRT followed by an APR $(n=50)$ or sphincter-saving surgery (SSS) $(n=72)$. Patients who had an APR showed a higher positive CRM rate and a higher postoperative complication rate than patients who has SSS. The 5-year local recurrence rates were $22 \%$ for an APR and $11.5 \%$ for SSS $(\mathrm{P}=0.03)$. The 5 -year overall survival rates were $52.9 \%$ for an APR and71.1\% for SSS ( $\mathrm{P}=0.03)$.

Eriken et al. [51] reported that percentage of tumor perforation during the surgery was higher for an APR than for a LAR $(28.5 \%$ vs. 9\%). Moreover, Chambers et al. [52] found that an incomplete resection ( $\mathrm{R} 1$ resection) was more common in an APR (25.7\%) than in a LAR $(6.5 \%)(\mathrm{P}<0.05)$. Consequently, the 5-year survival rates were $55 \%$ in the APR group and $67 \%$ in the LAR group $(\mathrm{P}=$ 0.05). Nagtegaal and Quirke [53] reported that an APR showed a higher rate of positive CRMs than the LAR, which was attributed to the high incidence of local recurrence in patients who underwent an APR. West et al. [54] analyzed the quality of specimens for an extralevator excision APR (total levator excision). They compared these with conventional APR specimens. The rate of positive CRMs was higher for the conventional APR than for an extralevator excision $(14.6 \%$ vs. $40.6 \%, \mathrm{P}=0.005)$. The incidence of
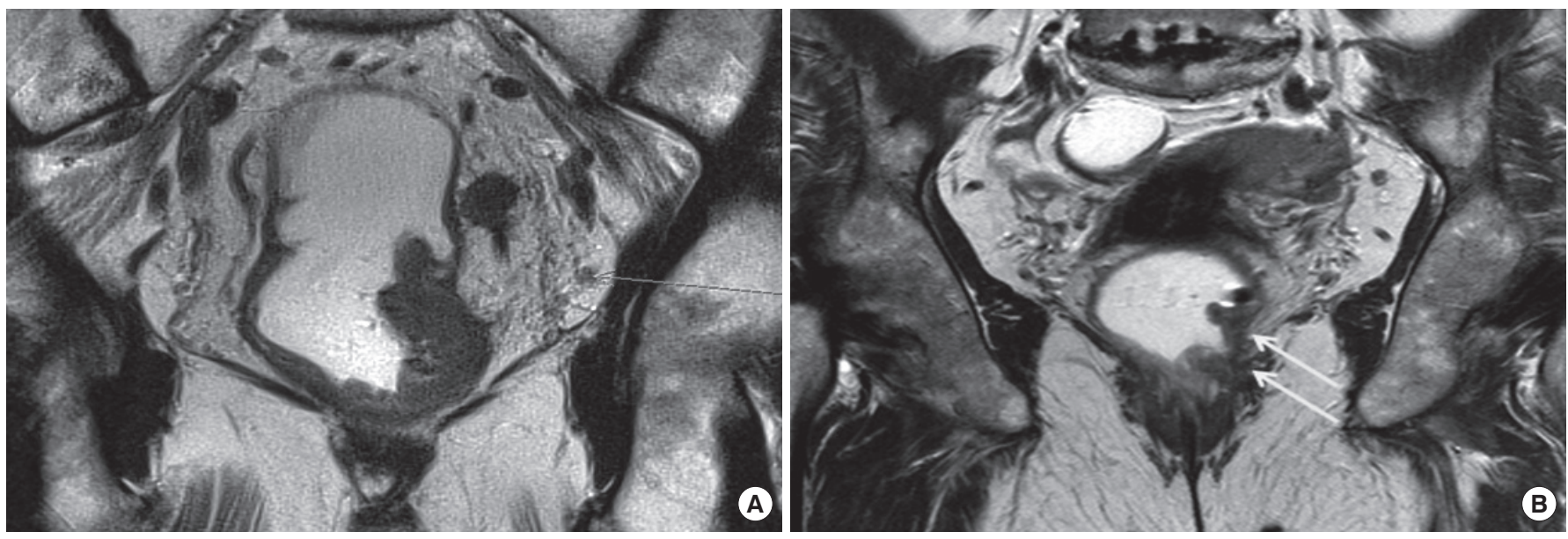

Fig. 1. Coronal axial view of rectal cancer close to the anorectal ring near the levator ani level in magnetic resonance imaging (MRI). (A) Rectal MRI before chemoradiation therapy (CRT) (Arrow indicates metastatic lymph node). (B) Rectal MRI after CRT. Arrows indicate rectal tumor. 
tumor perforation was 3.7\% for an extralevator excision and $22.8 \%$ for a conventional APR $(\mathrm{P}=0.005)$. Recently, many surgeons advocated TME with extralevator excision for an APR, so we must obtain cylindrically-shaped specimen rather than waisted ones. Therefore, Holm et al. [55] emphasized that an extended posterior perineal dissection with gluteus maximus flap reconstruction, which must be carried out in the prone position rather than the lithotomy position to avoid a positive CRM and tumor perforation. Stelzner et al. [56] analyzed patients who received an APR, either extended $(n=1,097)$ or standard $(n=4,147)$. They reported that the rates of inadvertent bowel perforation and CRM involvement for extended vs. standard APR were $4.1 \%$ vs. $10.4 \%$ ( $\mathrm{P}=$ $0.004)$ and $9.6 \%$ vs. $15.4 \%(\mathrm{P}=0.022)$, respectively. The local recurrence rate was $6.6 \%$ vs. $11.9 \%(\mathrm{P}<0.001)$ for both groups. They pointed out that the most critical zone for dissection in an APR was the anorectal junction. The dissection plane in the abdominal part comes close to the outer circumference of the tumor as surgeons follow the mesorectum toward the puborectalis sling in a standard APR; this approach results in a waist in the specimen, as well as high rates of inadvertent bowel perforation and positive CRMs. At this point, the dissection should be carried out toward the outer margin of the levatorani muscle. Actually, this part of the dissection must be carried out in prone Jack-knife position, and the levator ani muscle must be cut as close as possible to its origin, which is the best way to obtain a cylindrically-shaped APR specimen [56]. Recently, perineal dissection in the prone position has been started in our institute, and we are trying to determine the oncologic and technical advantages that make the dissection complete with a stretched levator ani and easy access.

\section{Changing surgical treatment modality for rectal cancer}

The surgical modality for mid and low rectal cancer has changed from a conventional open method to minimal invasive surgery using either a laparoscopic or a robotic technique. Regarding these issues, many studies in the literature have proven the safety and the feasibility of those technique, but long-term oncologic outcomes are still being investigated.

\section{CONCLUSION}

The surgical treatment for middle and distal rectal cancer has been known to be a very challenging issue. Following the current evidence might improve oncologic outcome and preserve anal sphincter, as well as sexual and voiding, function. A multidisciplinary approach has been shown to have a great impact on improving patients' treatment decision and survival. A definite treatment strategy algorithm is our future goal, and that goal can be obtained from a well-conducted clinical trial with high level of evidence.

Patient selection for each procedure to minimize morbidity and mortality should be considered as a future aim to improve quality of life. Thus, a tailored treatment option should be set up for each individual patient according to the patient general condition, tumor characteristics and tumor biology.

\section{CONFLICT OF INTEREST}

No potential conflict of interest relevant to this article was reported.

\section{REFERENCES}

1. van Gijn W, Marijnen CA, Nagtegaal ID, Kranenbarg EM, Putter $\mathrm{H}$, Wiggers $\mathrm{T}$, et al. Preoperative radiotherapy combined with total mesorectal excision for resectable rectal cancer: 12-year follow-up of the multicentre, randomised controlled TME trial. Lancet Oncol 2011;12:575-82.

2. Kapiteijn E, Marijnen CA, Nagtegaal ID, Putter H, Steup WH, Wiggers T, et al. Preoperative radiotherapy combined with total mesorectal excision for resectable rectal cancer. N Engl J Med 2001;345:638-46.

3. Cavaliere F, Pemberton JH, Cosimelli M, Fazio VW, Beart RW Jr. Coloanal anastomosis for rectal cancer. Long-term results at the Mayo and Cleveland Clinics. Dis Colon Rectum 1995;38:807-12.

4. Baik SH, Kim NK, Lee KY, Sohn SK, Cho CH. Hand-sewn coloanal anastomosis for distal rectal cancer: long-term clinical outcomes. J Gastrointest Surg 2005;9:775-80.

5. Kim NK, Lim DJ, Yun SH, Sohn SK, Min JS. Ultralow anterior resection and coloanal anastomosis for distal rectal cancer: functional and oncological results. Int J Colorectal Dis 2001;16:234-7.

6. Paty PB, Enker WE, Cohen AM, Lauwers GY. Treatment of rectal cancer by low anterior resection with coloanal anastomosis. Ann Surg 1994;219:365-73.

7. Aschele C, Cionini L, Lonardi S, Pinto C, Cordio S, Rosati G, et al. Primary tumor response to preoperative chemoradiation with or without oxaliplatin in locally advanced rectal cancer: pathologic results of the STAR-01 randomized phase III trial. J Clin Oncol 2011;29:2773-80.

8. Gerard JP, Azria D, Gourgou-Bourgade S, Martel-Laffay I, Hennequin C, Etienne PL, et al. Comparison of two neoadjuvant chemoradiotherapy regimens for locally advanced rectal cancer: results of the phase III trial ACCORD 12/0405-Prodige 2. J Clin Oncol 2010;28:1638-44.

9. Buess G, Kipfmuller K, Hack D, Grussner R, Heintz A, Junginger T. Technique of transanal endoscopic microsurgery. Surg Endosc 1988;2:71-5.

10. Chakravarti A, Compton CC, Shellito PC, Wood WC, Landry J, Machuta SR, et al. Long-term follow-up of patients with rectal cancer managed by local excision with and without adjuvant irradiation. Ann Surg 1999;230:49-54.

11. Garcia-Aguilar J, Mellgren A, Sirivongs P, Buie D, Madoff RD, Rothenberger DA. Local excision of rectal cancer without adjuvant therapy: a word of caution. Ann Surg 2000;231:345-51.

12. Paty PB, Nash GM, Baron P, Zakowski M, Minsky BD, Blumberg $\mathrm{D}$, et al. Long-term results of local excision for rectal cancer. Ann 
Surg 2002;236:522-29.

13. Endreseth BH, Myrvold HE, Romundstad P, Hestvik UE, Bjerkeset $\mathrm{T}$, Wibe A, et al. Transanal excision vs. major surgery for T1 rectal cancer. Dis Colon Rectum 2005;48:1380-8.

14. Madbouly KM, Remzi FH, Erkek BA, Senagore AJ, Baeslach CM, Khandwala F, et al. Recurrence after transanal excision of T1 rectal cancer: should we be concerned? Dis Colon Rectum 2005;48: 711-9.

15. Nascimbeni R, Nivatvongs S, Larson DR, Burgart LJ. Long-term survival after local excision for T1 carcinoma of the rectum. Dis Colon Rectum 2004;47:1773-9.

16. Ptok H, Marusch F, Meyer F, Schubert D, Koeckerling F, Gastinger I, et al. Oncological outcome of local vs radical resection of lowrisk pT1 rectal cancer. Arch Surg 2007;142:649-55.

17. You YN, Baxter NN, Stewart A, Nelson H. Is the increasing rate of local excision for stage I rectal cancer in the United States justified?: a nationwide cohort study from the National Cancer Database. Ann Surg 2007;245:726-33.

18. Gao JD, Shao YF, Bi JJ, Shi SS, Liang J, Hu YH. Local excision carcinoma in early stage. World J Gastroenterol 2003;9:871-3.

19. Garcia-Aguilar J, Shi Q, Thomas CR Jr, Chan E, Cataldo P, Marcet J, et al. A phase II trial of neoadjuvant chemoradiation and local excision for T2N0 rectal cancer: preliminary results of the ACOSOG Z6041 trial. Ann Surg Oncol 2012;19:384-91.

20. Baron PL, Enker WE, Zakowski MF, Urmacher C. Immediate vs. salvage resection after local treatment for early rectal cancer. Dis Colon Rectum 1995;38:177-81.

21. Moore JS, Cataldo PA, Osler T, Hyman NH. Transanal endoscopic microsurgery is more effective than traditional transanal excision for resection of rectal masses. Dis Colon Rectum 2008;51: 1026-30.

22. Christoforidis D, Cho HM, Dixon MR, Mellgren AF, Madoff RD, Finne CO. Transanal endoscopic microsurgery versus conventional transanal excision for patients with early rectal cancer. Ann Surg 2009;249:776-82.

23. Atallah S, Parra-Davila E, Debeche-Adams T, Albert M, Larach S. Excision of a rectal neoplasm using robotic transanal surgery (RTS): a description of the technique. Tech Coloproctol 2012;16: 389-92.

24. Atallah S, Albert M, Larach S. Transanal minimally invasive surgery: a giant leap forward. Surg Endosc 2010;24:2200-5.

25. Kitajima K, Fujimori T, Fujii S, Takeda J, Ohkura Y, Kawamata H, et al. Correlations between lymph node metastasis and depth of submucosal invasion in submucosal invasive colorectal carcinoma: a Japanese collaborative study. J Gastroenterol 2004;39:534-43.

26. Russell AH, Harris J, Rosenberg PJ, Sause WT, Fisher BJ, Hoffman JP, et al. Anal sphincter conservation for patients with adenocarcinoma of the distal rectum: long-term results of radiation therapy oncology group protocol 89-02. Int J Radiat Oncol Biol Phys 2000;46:313-22.

27. Min BS, Kim NK, Ko YT, Lee KY, Baek SH, Cho CH, et al. Longterm oncologic results of patients with distal rectal cancer treated by local excision with or without adjuvant treatment. Int J Colorectal Dis 2007;22:1325-30.

28. Greenberg JA, Shibata D, Herndon JE 2nd, Steele GD Jr, Mayer R, Bleday R. Local excision of distal rectal cancer: an update of cancer and leukemia group B 8984. Dis Colon Rectum 2008;51: 1185-91.

29. Lezoche G, Baldarelli M, Guerrieri M, Paganini AM, De Sanctis A, Bartolacci S, et al. A prospective randomized study with a 5-year minimum follow-up evaluation of transanal endoscopic microsurgery versus laparoscopic total mesorectal excision after neoadjuvant therapy. Surg Endosc 2008;22:352-8.

30. Bokkerink GM, de Graaf EJ, Punt CJ, Nagtegaal ID, Rütten H, Nuyttens JJ, et al. The CARTS study: Chemoradiation therapy for rectal cancer in the distal rectum followed by organ-sparing transanal endoscopic microsurgery. BMC Surg 2011;11:34..

31. Callender GG, Das P, Rodriguez-Bigas MA, Skibber JM, Crane $\mathrm{CH}$, Krishnan S, et al. Local excision after preoperative chemoradiation results in an equivalent outcome to total mesorectal excision in selected patients with T3 rectal cancer. Ann Surg Oncol 2010;17:441-7.

32. Habr-Gama A, Perez RO, Nadalin W, Sabbaga J, Ribeiro U Jr, Silva e Sousa AH Jr, et al. Operative versus nonoperative treatment for stage 0 distal rectal cancer following chemoradiation therapy: long-term results. Ann Surg 2004;240:711-7.

33. Kang JH, Kim YC, Kim H, Kim YW, Hur H, Kim JS, et al. Tumor volume changes assessed by three-dimensional magnetic resonance volumetry in rectal cancer patients after preoperative chemoradiation: the impact of the volume reduction ratio on the prediction of pathologic complete response. Int J Radiat Oncol Biol Phys 2010;76:1018-25.

34. Maas M, Beets-Tan RG, Lambregts DM, Lammering G, Nelemans PJ, Engelen SM, et al. Wait-and-see policy for clinical complete responders after chemoradiation for rectal cancer. J Clin Oncol 2011;29:4633-40.

35. Glynne-Jones R, Hughes R. Critical appraisal of the 'wait and see' approach in rectal cancer for clinical complete responders after chemoradiation. Br J Surg 2012;99:897-909.

36. Habr-Gama A, Perez RO, Sao Juliao GP, Proscurshim I, GamaRodrigues J. Nonoperative approaches to rectal cancer: a critical evaluation. Semin Radiat Oncol 2011;21:234-9.

37. Parks AG, Percy JP. Resection and sutured colo-anal anastomosis for rectal carcinoma. Br J Surg 1982;69:301-4.

38. Tilney HS, Tekkis PP. Extending the horizons of restorative rectal surgery: intersphincteric resection for low rectal cancer. Colorectal Dis 2008;10:3-15.

39. Portier G, Ghouti L, Kirzin S, Guimbaud R, Rives M, Lazorthes F. Oncological outcome of ultra-low coloanal anastomosis with and without intersphincteric resection for low rectal adenocarcinoma. Br J Surg 2007;94:341-5.

40. Saito N, Moriya Y, Shirouzu K, Maeda K, Mochizuki H, Koda K, et al. Intersphincteric resection in patients with very low rectal cancer: a review of the Japanese experience. Dis Colon Rectum 
2006;49(10 Suppl):S13-22.

41. Schiessel R, Novi G, Holzer B, Rosen HR, Renner K, Holbling N, et al. Technique and long-term results of intersphincteric resection for low rectal cancer. Dis Colon Rectum 2005;48:1858-65.

42. Rullier E, Laurent C, Bretagnol F, Rullier A, Vendrely V, Zerbib F. Sphincter-saving resection for all rectal carcinomas: the end of the 2-cm distal rule. Ann Surg 2005;241:465-9.

43. Bozzetti F, Mariani L, Miceli R, Doci R, Montalto F, Andreola S, et al. Cancer of the low and middle rectum: local and distant recurrences, and survival in 350 radically resected patients. J Surg Oncol 1996;62:207-13.

44. Zaheer S, Pemberton JH, Farouk R, Dozois RR, Wolff BG, Ilstrup D. Surgical treatment of adenocarcinoma of the rectum. Ann Surg 1998;227:800-11.

45. Saito N, Sugito M, Ito M, Kobayashi A, Nishizawa Y, Yoneyama Y, et al. Oncologic outcome of intersphincteric resection for very low rectal cancer. World J Surg 2009;33:1750-6.

46. Heald RJ, Smedh RK, Kald A, Sexton R, Moran BJ. Abdominoperineal excision of the rectum: an endangered operation. Norman Nigro Lectureship. Dis Colon Rectum 1997;40:747-51.

47. Law WL, Chu KW. Abdominoperineal resection is associated with poor oncological outcome. Br J Surg 2004;91:1493-9.

48. Marr R, Birbeck K, Garvican J, Macklin CP, Tiffin NJ, Parsons WJ, et al. The modern abdominoperineal excision: the next challenge after total mesorectal excision. Ann Surg 2005;242:74-82.

49. Wibe A, Moller B, Norstein J, Carlsen E, Wiig JN, Heald RJ, et al. A national strategic change in treatment policy for rectal cancer: implementation of total mesorectal excision as routine treatment in Norway. A national audit. Dis Colon Rectum 2002;45:857-66.

50. Kim JS, Hur H, Kim NK, Kim YW, Cho SY, Kim JY, et al. Oncologic outcomes after radical surgery following preoperative chemoradiotherapy for locally advanced lower rectal cancer: abdominoperineal resection versus sphincter-preserving procedure. Ann Surg Oncol 2009;16:1266-73.

51. Eriksen MT, Wibe A, Syse A, Haffner J, Wiig JN; Norwegian Rectal Cancer Group, et al. Inadvertent perforation during rectal cancer resection in Norway. Br J Surg 2004;91:210-6.

52. Chambers W, Khan A, Waters R, Lindsey I, George B, Mortensen $\mathrm{N}$, et al. Examination of outcome following abdominoperineal resection for adenocarcinoma in Oxford. Colorectal Dis 2010;12: 1192-7.

53. Nagtegaal ID, Quirke P. What is the role for the circumferential margin in the modern treatment of rectal cancer? J Clin Oncol 2008;26:303-12.

54. West NP, Finan PJ, Anderin C, Lindholm J, Holm T, Quirke P. Evidence of the oncologic superiority of cylindrical abdominoperineal excision for low rectal cancer. J Clin Oncol 2008;26: 3517-22.

55. Holm T, Ljung A, Haggmark T, Jurell G, Lagergren J. Extended abdominoperineal resection with gluteus maximus flap reconstruction of the pelvic floor for rectal cancer. Br J Surg 2007;94: 232-8.
56. Stelzner S, Koehler C, Stelzer J, Sims A, Witzigmann H. Extended abdominoperineal excision vs. standard abdominoperineal excision in rectal cancer: a systematic overview. Int J Colorectal Dis 2011;26:1227-40.

57. Mellgren A, Sirivongs P, Rothenberger DA, Madoff RD, GarciaAguilar J. Is local excision adequate therapy for early rectal cancer? Dis Colon Rectum 2000;43:1064-71.

58. Bentrem DJ, Okabe S, Wong WD, Guillem JG, Weiser MR, Temple LK, et al. T1 adenocarcinoma of the rectum: transanal excision or radical surgery? Ann Surg 2005;242:472-7.

59. Folkesson J, Johansson R, Pahlman L, Gunnarsson U. Populationbased study of local surgery for rectal cancer. Br J Surg 2007;94: 1421-6.

60. Nash GM, Weiser MR, Guillem JG, Temple LK, Shia J, Gonen M, et al. Long-term survival after transanal excision of T1 rectal cancer. Dis Colon Rectum 2009;52:577-82.

61. Onaitis MW, Noone RB, Fields R, Hurwitz H, Morse M, Jowell P, et al. Complete response to neoadjuvant chemoradiation for rectal cancer does not influence survival. Ann Surg Oncol 2001;8: 801-6.

62. Medich D, McGinty J, Parda D, Karlovits S, Davis C, Caushaj P, et al. Preoperative chemoradiotherapy and radical surgery for locally advanced distal rectal adenocarcinoma: pathologic findings and clinical implications. Dis Colon Rectum 2001;44:1123-8.

63. Hiotis SP, Weber SM, Cohen AM, Minsky BD, Paty PB, Guillem JG, et al. Assessing the predictive value of clinical complete response to neoadjuvant therapy for rectal cancer: an analysis of 488 patients. J Am Coll Surg 2002;194:131-5.

64. Zmora O, Dasilva GM, Gurland B, Pfeffer R, Koller M, Nogueras JJ, et al. Does rectal wall tumor eradication with preoperative chemoradiation permit a change in the operative strategy? Dis Colon Rectum 2004;47:1607-12.

65. Stipa F, Lucandri G, Ferri M, Casula G, Ziparo V. Local excision of rectal cancer with transanal endoscopic microsurgery (TEM). Anticancer Res 2004;24(2C):1167-72.

66. Bedrosian I, Rodriguez-Bigas MA, Feig B, Hunt KK, Ellis L, Curley SA, et al. Predicting the node-negative mesorectum after preoperative chemoradiation for locally advanced rectal carcinoma. J Gastrointest Surg 2004;8:56-62.

67. Kim DW, Kim DY, Kim TH, Jung KH, Chang HJ, Sohn DK, et al. Is $\mathrm{T}$ classification still correlated with lymph node status after preoperative chemoradiotherapy for rectal cancer? Cancer 2006; 106:1694-700.

68. Hughes R, Glynne-Jones R, Grainger J, Richman P, Makris A, Harrison M, et al. Can pathological complete response in the primary tumour following pre-operative pelvic chemoradiotherapy for T3-T4 rectal cancer predict for sterilisation of pelvic lymph nodes, a low risk of local recurrence and the appropriateness of local excision? Int J Colorectal Dis 2006;21:11-7.

69. Coco C, Manno A, Mattana C, Verbo A, Rizzo G, Valentini V, et al. The role of local excision in rectal cancer after complete response to neoadjuvant treatment. Surg Oncol 2007;16 Suppl 1: 
S101-4.

70. Habr-Gama A, Perez RO, Proscurshim I, Rawet V, Pereira DD, Sousa AH, et al. Absence of lymph nodes in the resected specimen after radical surgery for distal rectal cancer and neoadjuvant chemoradiation therapy: what does it mean? Dis Colon Rectum 2008;51:277-83.

71. Schell SR, Zlotecki RA, Mendenhall WM, Marsh RW, Vauthey JN, Copeland EM 3rd. Transanal excision of locally advanced rectal cancers downstaged using neoadjuvant chemoradiotherapy. J Am Coll Surg 2002;194:584-90.

72. Hershman MJ, Myint AS, Makin CA. Multi-modality approach in curative local treatment of early rectal carcinomas. Colorectal Dis 2003;5:445-50.

73. Bonnen M, Crane C, Vauthey JN, Skibber J, Delclos ME, Rodriguez-Bigas $\mathrm{M}$, et al. Long-term results using local excision after preoperative chemoradiation among selected $\mathrm{T} 3$ rectal cancer $\mathrm{pa}-$ tients. Int J Radiat Oncol Biol Phys 2004;60:1098-105.

74. Borschitz T, Wachtlin D, Mohler M, Schmidberger H, Junginger T. Neoadjuvant chemoradiation and local excision for T2-3 rectal cancer. Ann Surg Oncol 2008;15:712-20.

75. Nair RM, Siegel EM, Chen DT, Fulp WJ, Yeatman TJ, Malafa MP, et al. Long-term results of transanal excision after neoadjuvant chemoradiation for $\mathrm{T} 2$ and $\mathrm{T} 3$ adenocarcinomas of the rectum. J Gastrointest Surg 2008;12:1797-805.

76. Huh JW, Jung EJ, Park YA, Lee KY, Sohn SK. Preoperative chemoradiation followed by transanal excision for rectal cancer. J Surg Res 2008;148:244-50.

77. Kundel Y, Brenner R, Purim O, Peled N, Idelevich E, Fenig E, et al. Is local excision after complete pathological response to neoadjuvant chemoradiation for rectal cancer an acceptable treatment option? Dis Colon Rectum 2010;53:1624-31. 